\title{
Different transporter systems regulate extracellular GABA from vesicular and non-vesicular sources
}

\section{Inseon Song ${ }^{1}$, Kirill Volynski ${ }^{2}$, Tanja Brenner ${ }^{1}$, Yuri Ushkaryov ${ }^{3}$, Matthew Walker $^{2}$ and Alexey Semyanov ${ }^{1,4 *}$}

${ }^{1}$ RIKEN Brain Science Institute, Wako-shi, Saitama, Japan

2 Department of Clinical and Experimental Epilepsy, UCL Institute of Neurology, London, UK

${ }^{3}$ Medway School of Pharmacy, University of Kent, Chatham Maritime, UK

${ }^{4}$ Department of Neurodynamics and Neurobiology, University of Nizhny Novgorod, Nizhny Novgorod, Russia

\section{Edited by:}

Enrico Cherubini, International

School for Advanced Studies, Italy

\section{Reviewed by:}

Istvan Mody, University of California, Los Angeles, USA

Annalisa Scimemi, National

Institutes of Health, USA

\section{*Correspondence:}

Alexey Semyanov, RIKEN Brain Science Institute, 2-1 Hirosawa,

Wako-shi, Saitama 351-0198, Japan. e-mail: semyanov@brain.riken.jp
Tonic GABA type $A\left(G_{A B A}\right)$ conductance is a key factor regulating neuronal excitability and computation in neuronal networks. The magnitude of the tonic $G_{A B} A_{A}$ conductance depends on the concentration of ambient GABA originating from vesicular and non-vesicular sources and is tightly regulated by GABA uptake. Here we show that the transport system regulating ambient GABA responsible for tonic $\mathrm{GABA}_{\mathrm{A}}$ conductances in hippocampal CA1 interneurons depends on its source. In mice, GABA from vesicular sources is regulated by mouse GABA transporter 1 (mGAT1), while that from non-vesicular sources by mouse GABA transporters $3 / 4$ (mGAT3/4). This finding suggests that the two transporter systems do not just provide backup for each other, but regulate distinct signaling pathways. This allows individual tuning of the two signaling systems and indicates that drugs designed to act at specific transporters will have distinct therapeutic actions.

Keywords: GABA transporter, tonic $\mathrm{GABA}_{\mathrm{A}}$ conductance, mutant $\alpha$-latrotoxin, GABA source, extrasynaptic signaling, GABA, interneurons

\section{INTRODUCTION}

Tonic activation of extrasynaptic GABA type A receptors $\left(\mathrm{GABA}_{\mathrm{A}}\right)$ by ambient GABA is a major form of GABAergic signaling in the central nervous system (Semyanov et al., 2004; Farrant and Nusser, 2005; Glykys and Mody, 2007a; Walker and Semyanov, 2008). It can be recorded in voltage-clamped neurons as the part of holding current $\left(I_{\text {hold }}\right)$ that is sensitive to $\mathrm{GABA}_{\mathrm{A}}$ receptor antagonists (termed tonic $\mathrm{GABA}_{\mathrm{A}}$ current). The expression of tonic $\mathrm{GABA}_{\mathrm{A}}$ currents is cell-type specific, and this specificity determines the network effect of this form of signaling (Semyanov et al., 2004). For example, in the hippocampal CA1 region, tonic $\mathrm{GABA}_{\mathrm{A}}$ currents are significantly larger in interneurons than in pyramidal cells (Semyanov et al., 2003; Scimemi et al., 2005), and this difference may be due to a more efficient GABA uptake around pyramidal cells. Tonic currents also exert different effects on interneuron and pyramidal cell excitability. In the adult brain, GABA hyperpolarizes hippocampal pyramidal neurons (Glickfeld et al., 2009), whereas it depolarizes interneurons (Michelson and Wong, 1991; Banke and McBain, 2006; Vida et al., 2006; Song et al., 2011). Consequently, tonic $\mathrm{GABA}_{\mathrm{A}}$ conductances have inhibitory effects on pyramidal neurons, whereas low tonic $\mathrm{GABA}_{\mathrm{A}}$ conductances have excitatory effects on interneurons (Song et al., 2011). When the ambient GABA concentrations increase, tonic $\mathrm{GABA}_{\mathrm{A}}$ conductances become larger and the shunting overpowers the excitatory effect of depolarization, rendering the overall effect of the tonic $\mathrm{GABA}_{\mathrm{A}}$ conductance inhibitory. This phenomenon is particularly interesting given the diverse roles of interneurons in the hippocampus, such as rhythmic activity, synchronization of pyramidal cells firing, feedforward, and feedback inhibition (see for review, Kullmann, 2011). Thus mechanisms changing ambient GABA concentrations around interneurons, such as GABA release and uptake, can have profound functional effects. Ambient GABA originates from a number of synaptic and non-synaptic sources in the brain. The magnitude of tonic $\mathrm{GABA}_{\mathrm{A}}$ currents in rat CA1 pyramidal neurons correlates with the frequency of spontaneous inhibitory post-synaptic currents (sIPSCs) when rat GAT1 (rGAT1) is blocked, suggesting a synaptic contribution to ambient GABA around these cells (Glykys and Mody, 2007b). Astrocytic GABA release has been demonstrated in the olfactory bulb (Kozlov et al., 2006) and cerebellum (Lee et al., 2010). Dendritic exocytotic GABA release has been reported in the neocortex (Zilberter et al., 1999). Extracellular GABA is cleared by GABA transporters, classified as mouse GABA transporter 1 (mGAT1), mGAT2, mGAT3, and mGAT4 in the mouse [homologs in rat: mGAT1 $\sim$ rGAT1, mGAT2 betaine/GABA transporter 1 (BTG1), mGAT3 rGAT2, mGAT4 $\sim$ rGAT3]. In rats, rGAT1 and rGAT2/3 blockers synergistically modulate tonic $\mathrm{GABA}_{\mathrm{A}}$ conductances (Keros and Hablitz, 2005; Jin et al., 2011). The relative impact of different transporters on ambient GABA originating from different sources, however, has been unknown. Here we show in mouse hippocampal CA1 stratum (str.) radiatum interneurons that mGAT1 and mGAT3/4 selectively regulate tonic $\mathrm{GABA}_{\mathrm{A}}$ currents mediated by GABA originating from vesicular and non-vesicular sources, respectively. 


\section{MATERIALS AND METHODS ETHICAL APPROVAL}

All procedures involving animals were approved by the institutional Animal Care and Use committee at RIKEN.

\section{SLICE PREPARATION}

Hippocampal slices $(350 \mu \mathrm{m})$ were obtained from 3- to 4-weekold C57BL/6J mice. After dissection, the hippocampi were sliced using a vibration microtome (Microm HM650V, Germany). Transverse hippocampal slices were prepared in ice-cold slicing solution containing (in $\mathrm{mM}$ ): $87 \mathrm{NaCl}, 2.5 \mathrm{KCl}, 7 \mathrm{MgCl}_{2}$, $0.5 \mathrm{CaCl}_{2}, 26.2 \mathrm{NaHCO}_{3}, 1.25 \mathrm{NaH}_{2} \mathrm{PO}_{4}, 25$ glucose, and 50 sucrose, and saturated with $95 \% \mathrm{CO}_{2} / 5 \% \mathrm{O}_{2}$. After preparation, the slices were maintained at room temperature in a submerged chamber with storage solution containing (in $\mathrm{mM}$ ): $119 \mathrm{NaCl}$, $2.5 \mathrm{KCl}, 1.3 \mathrm{MgSO}_{4}, 1 \mathrm{CaCl}_{2}, 26.2 \mathrm{NaHCO}_{3}, 1 \mathrm{NaH}_{2} \mathrm{PO}_{4}$, and 11 glucose, and saturated with $95 \% \mathrm{CO}_{2} / 5 \% \mathrm{O}_{2}$.

\section{WHOLE-CELL PATCH CLAMP RECORDING}

After $1 \mathrm{~h}$ incubation, slices were transferred to the recording chamber and superfused at $32-34^{\circ} \mathrm{C}$ with external solution (same as above, but containing $2.5 \mathrm{mM} \mathrm{CaCl}_{2}$ ). AMPA/kainate, $\mathrm{NMDA}$, and $\mathrm{GABA}_{\mathrm{B}}$ receptors were blocked with $25 \mu \mathrm{M}$ NBQX, $50 \mu \mathrm{M}$ APV, and $5 \mu \mathrm{M}$ CGP52432 (Tocris Cookson, Bristol, UK), respectively.

$\alpha$-Latrotoxin from the black widow spider venom stimulates neurotransmitter release by acting on presynaptic receptors (Ushkaryov et al., 2008; Silva et al., 2009). $\alpha$-Latrotoxin mutant $\left(\right.$ LTX $\left.^{\mathrm{N} 4 \mathrm{C}}\right)$ in which four amino acids were inserted between the main domains (Ichtchenko et al., 1998) was used to stimulate spontaneous vesicular exocytosis (Volynski et al., 2003). Stock aliquots of $\operatorname{LTX}^{\mathrm{N} 4 \mathrm{C}}(17-42 \mathrm{nM})$ were stored at $-28^{\circ} \mathrm{C}$ in non-freon Nihon freezer GS-1356HC (Japan). LTX ${ }^{\mathrm{N} 4 \mathrm{C}}$ was focally applied to the recording chamber at a concentration of $0.1 \mathrm{nM}$ near the recording pipette after stopping the superfusion (Capogna et al., 2003). Perfusion was resumed when the frequency of sIPSCs began to increase $(0.5-10 \mathrm{~min}$ after toxin application). Such an interruption in perfusion had no effect on control recordings. In experiments where vesicular release was blocked, slices were pre-treated for at least $2.5 \mathrm{~h}$ in $4 \mu \mathrm{M}$ bafilomycin A1 (Wako Chemicals, Japan) while control slices from the same animal were kept in external solution without bafilomycin A1. All recordings were made from CA1 str.radiatum interneurons visually identified with an infrared differential interference contrast microscope (Olympus BX51WI, Japan). Whole-cell pipettes used in voltage-clamp recordings contained (in mM): $130 \mathrm{CsCl}, 8 \mathrm{NaCl}, 10 \mathrm{Cs}$-HEPES, 2 EGTA, 0.2 $\mathrm{MaCl}_{2}, 2 \mathrm{MgATP}, 0.3 \mathrm{Na}_{3} \mathrm{GTP}$, and 5 QX314Br (pH 7.2, osmolarity $295 \mathrm{mOsm}$ ). The data were acquired with a Multiclamp700B amplifier (Molecular Devices, Sunnyvale, CA), filtered at $3 \mathrm{kHz}$, and digitized at $10 \mathrm{kHz}$ using a NI PCI-6221 data acquisition card (National Instruments, Austin, TX). The data were analyzed without further re-sampling. Sample traces were also taken at the same rate; the long traces (>30 s) showing the $I_{\text {hold }}$ were re-sampled at $10 \mathrm{~Hz}$ for illustration purposes. Frequency, amplitude, and area of sIPSCs were analyzed off-line with MiniAnalysis (Synaptosoft Inc, Decatur, GA) and Clampfit (Molecular Devices) programs.
Whole-cell voltage-clamp recordings were performed at $-70 \mathrm{mV}$. Tonic $\mathrm{GABA}_{\mathrm{A}}$ currents $\left(\Delta I_{\text {hold }}\right)$ were calculated as the difference between the baseline $I_{\text {hold }}$ and the $I_{\text {hold }}$ in the presence of the drug affecting tonic $\mathrm{GABA}_{\mathrm{A}}$ currents. To estimate $I_{\text {hold }}$ in control and drug conditions, we plotted all-points histograms over $20 \mathrm{~s}$ of recordings in each case (Glykys and Mody, 2007b). These histograms have a peak which corresponds to mean $I_{\text {hold }}$ while fluctuations in the holding current affect the width and skewness of the histograms. This method was specifically developed to overcome bias due to the presence of IPSCs on the $I_{\text {hold }}$ measurements. The time-averaged currents mediated by sIPSCs $\left(I_{\text {spont }}\right)$ were calculated as the mean charge transfer of sIPSCs (area under the IPSCs) multiplied by their frequency (Semyanov et al., 2003).

\section{STATISTICS}

Statistical analysis was performed using Excel (Microsoft, USA) and Origin8 (OriginLab, USA). Data were presented as mean \pm S.E.M; ${ }^{*} P<0.05,{ }^{* *} P<0.01$ paired, unpaired, or onesample Student's $t$-test as stated in the text. A $P$-value of less than 0.05 was considered statistically significant. Two-Way ANOVA was used to assess the effects and interaction of GABA transporter blockers and bafilomycin A1.

\section{RESULTS

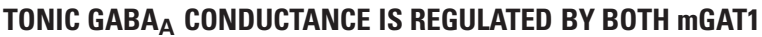 AND mGAT3/4 TRANSPORTERS}

sIPSCs and $I_{\text {hold }}$ were recorded in voltage-clamped CA1 str.radiatum interneurons in mouse hippocampal slices in the presence of $\alpha$-amino-3-hydroxy-5-methyl-4-isoxazolepropionic acid (AMPA)/kainate, N-methyl-D-aspartate (NMDA), and GABA type $B\left(G A B A_{B}\right)$ receptor antagonists to isolate $G_{A B A}$ receptor currents. The transient inward currents were mediated by $\mathrm{GABA}_{\mathrm{A}}$ receptors (sIPSCs) and blocked by application of the $\mathrm{GABA}_{\mathrm{A}}$ receptor antagonist picrotoxin $(100 \mu \mathrm{M}$; Figure $2 \mathrm{~A})$. Picrotoxin also produced a shift in $I_{\text {hold }}$, which represents the tonic $\mathrm{GABA}_{\mathrm{A}}$ current. Then we tested how different transporter subtypes regulate this baseline tonic $\mathrm{GABA}_{\mathrm{A}}$ current. The mGAT1 blocker NO711 $(10 \mu \mathrm{M})$ and the mGAT3/4 blocker SNAP5114 $(100 \mu \mathrm{M})$ both significantly increased $I_{\text {hold }}$ (Table 1, Figure 1), suggesting that elimination of either transporter subtype leads to increases in ambient GABA. NO711 and SNAP5114 together increased $I_{\text {hold }}$ more than the sum of the effects of individual

Table 1 | Effect of mGAT1 and mGAT3/4 blockers on $I_{\text {hold }}$ in mouse interneurons.

\begin{tabular}{|c|c|c|c|}
\hline & $\begin{array}{l}\Delta / \text { hold } \\
\text { (NO711) }\end{array}$ & $\begin{array}{l}\Delta / \text { hold } \\
\text { (SNAP5114) }\end{array}$ & $P_{\text {(N0711 vs.SNAP5114) }}$ \\
\hline Control & $\begin{array}{l}19.35 \pm 5.09 \\
(n=6)\end{array}$ & $\begin{array}{l}12.12 \pm 2.28 \\
(n=7)\end{array}$ & 0.100 \\
\hline Bafilomycin A1 & $\begin{array}{l}7.56 \pm 1.74 \\
(n=6)\end{array}$ & $\begin{array}{l}17.03 \pm 4.02 \\
(n=6)\end{array}$ & $0.028 *$ \\
\hline$P_{\text {(controlvs.baf.A1) }}$ & $0.026^{*}$ & 0.149 & \\
\hline
\end{tabular}

Data are presented as mean \pm S.E.M; P-values for unpaired t-test, ${ }^{*} P<0.05$. 
blockers suggesting a synergetic effect of the two drugs on extracellular GABA elevation.

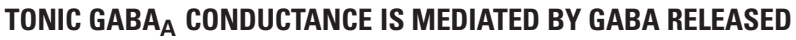 FROM BOTH VESICULAR AND NON-VESICULAR SOURCES}

It was unclear whether GABA elevations during blockade of each transporter system originated from the same or different sources. Indeed, the different locations of rGAT1 (which is predominantly located on neurons) and rGAT3 (which is located on astrocytes) indicate that these transporters may specifically regulate GABA originating from different sources (Ribak et al., 1996; Heja et al., 2009, 2012; Shigetomi et al., 2012). First, we identified the proportion of tonic $\mathrm{GABA}_{\mathrm{A}}$ conductance in interneurons that is mediated by non-vesicular GABA release. We compared the tonic $\mathrm{GABA}_{\mathrm{A}}$ current in control slices and in slices pretreated with a selective inhibitor of vacuolar $\mathrm{H}^{+}$-ATPases, bafilomycin A1, which prevents GABA loading into synaptic

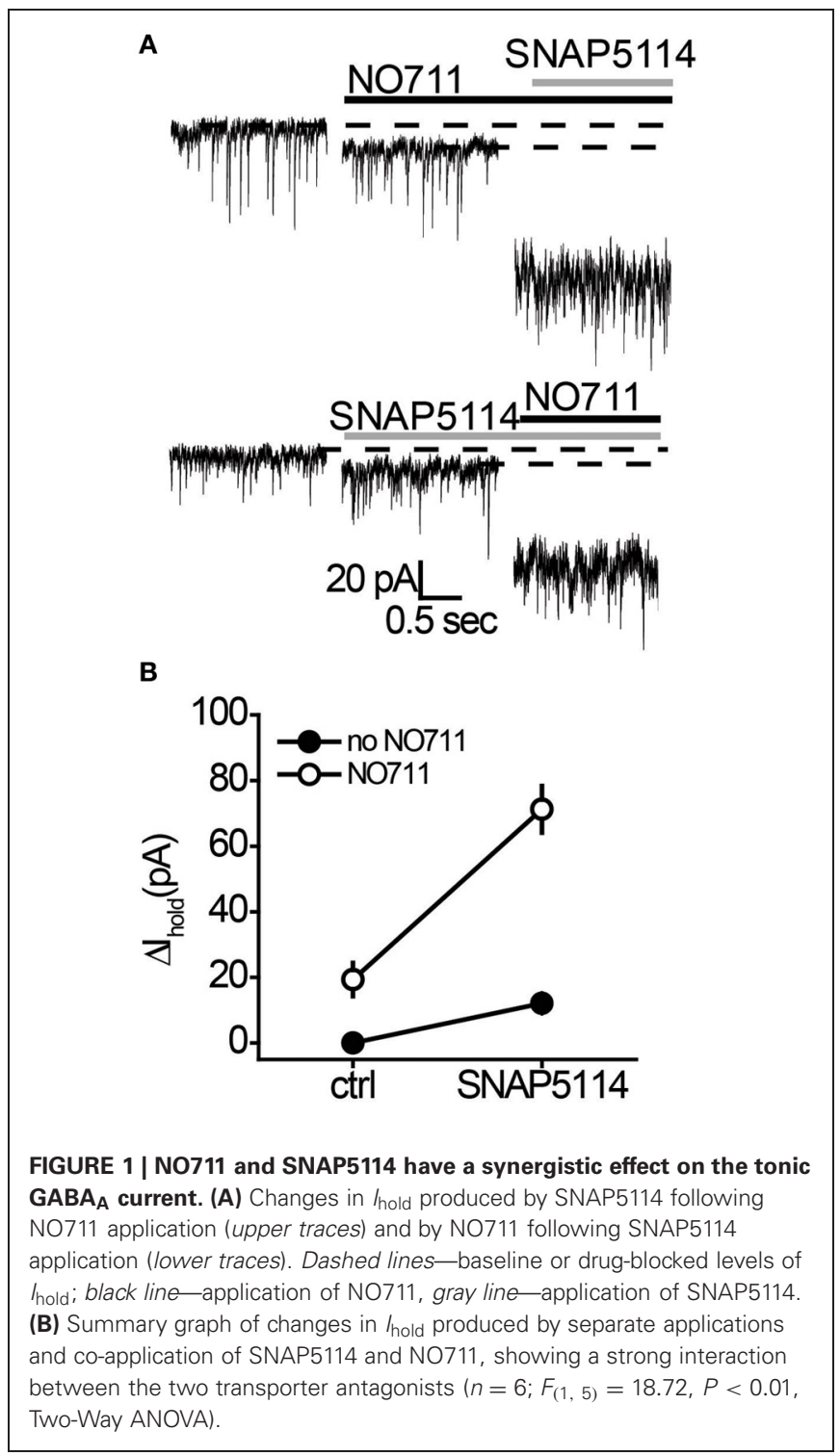

vesicles and thus vesicular GABA release. The slices pretreated with bafilomycin A1 were completely devoid of sIPSCs, confirming total blockade of vesicular release (Figures 2A,B). In these slices, application of picrotoxin revealed significant tonic $\mathrm{GABA}_{\mathrm{A}}$ currents in CA1 interneurons $(7.9 \pm 2.8 \mathrm{pA}, n=6, P=0.028$ one-sample $t$-test), which constituted $40 \%$ of the tonic $\mathrm{GABA}_{\mathrm{A}}$ current revealed by picrotoxin in control slices not treated with bafilomycin A1 $(19.6 \pm 3.2 \mathrm{pA}, n=14, P=0.015$ one-sample $t$-test; Figure 2C; $P=0.0031$ for the difference between control and bafilomycin A1-treated slices, unpaired $t$-test). Because picrotoxin also blocks homomeric glycine receptors, we confirmed that tonic current in bafilomycin A1-treated slices is GABAergic using $25 \mu \mathrm{M}$ bicuculline $(9.17 \pm 2.40 \mathrm{pA}, n=6, P=$ 0.007 one-sample $t$-test; Figure $3 \mathrm{~A}$ ). Because bafilomycin A1 also affects exocytosis and therefore can potentially affect the neuronal receptor density (Johnson et al., 1993; Presley et al., 1997), we tested whether the responses to exogenous GABA were affected by bafilomycin A1 treatment. The tonic current produced by exogenous application of $10 \mu \mathrm{M}$ GABA did not differ significantly between control and treated slices (Figure 3B).

\section{mGAT3/4 REGULATES GABA ORIGINATING FROM NON-VESICULAR SOURCES}

We then tested the effect of mGAT1 and mGAT3/4 blockers on the tonic $\mathrm{GABA}_{\mathrm{A}}$ current in the presence of bafilomycin A1. The mGAT1 blocker NO711 led to a smaller increase in the tonic $\mathrm{GABA}_{\mathrm{A}}$ current in the absence of vesicular release (Table 1, Figure 4A). However, the increase was significant $(P=0.007$, paired $t$-test), suggesting that mGAT1 limits the contribution of both synaptic spillover and also non-vesicular release to ambient GABA concentrations. In contrast, the tonic $\mathrm{GABA}_{\mathrm{A}}$

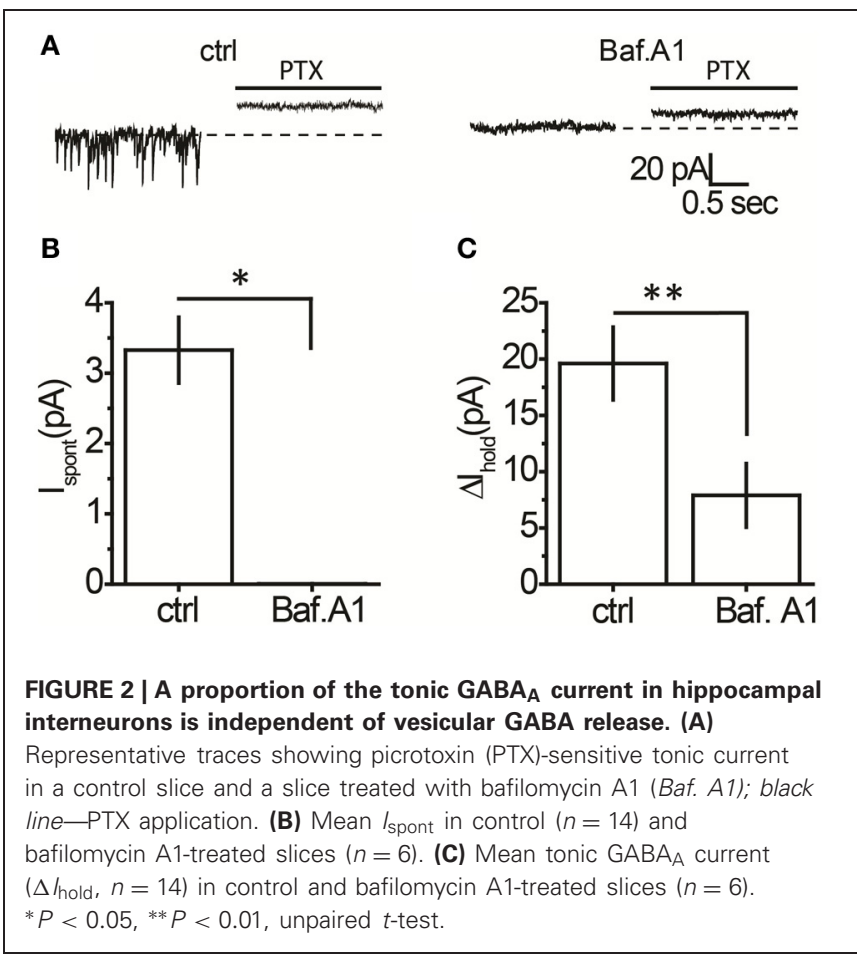


current increase caused by mGAT3/4 blocker SNAP5114 was not significantly different in the absence or presence of vesicular release (Table 1, Figure 4B), suggesting that, in slices at baseline conditions, mGAT3/4 regulates GABA originating largely
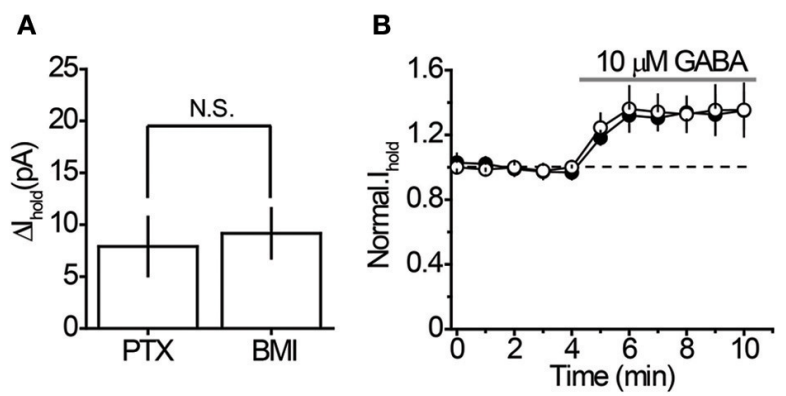

FIGURE 3 | Characteristics of the tonic GABA current in bafilomycin A1-treated slices. (A) $100 \mu \mathrm{M}$ picrotoxin (PTX, $n=6$ ) and $25 \mu \mathrm{M}$ bicuculline (BMI, $n=5$ ) revealed similar tonic $\mathrm{GABA}_{\mathrm{A}}$ current in CA1 interneurons of bafilomycin A1-treated slices. (B) Sensitivity of / hold to exogenous GABA $(10 \mu \mathrm{M})$ in control $(n=6)$ and bafilomycin A1-treated slices $(n=7)$. Black circles-/hold in control slices, white circles-/hold in bafilomycin A1-treated slices normalized to corresponding baseline values (dashed line). Gray line -GABA application. N.S. $P>0.05$, unpaired $t$-test.

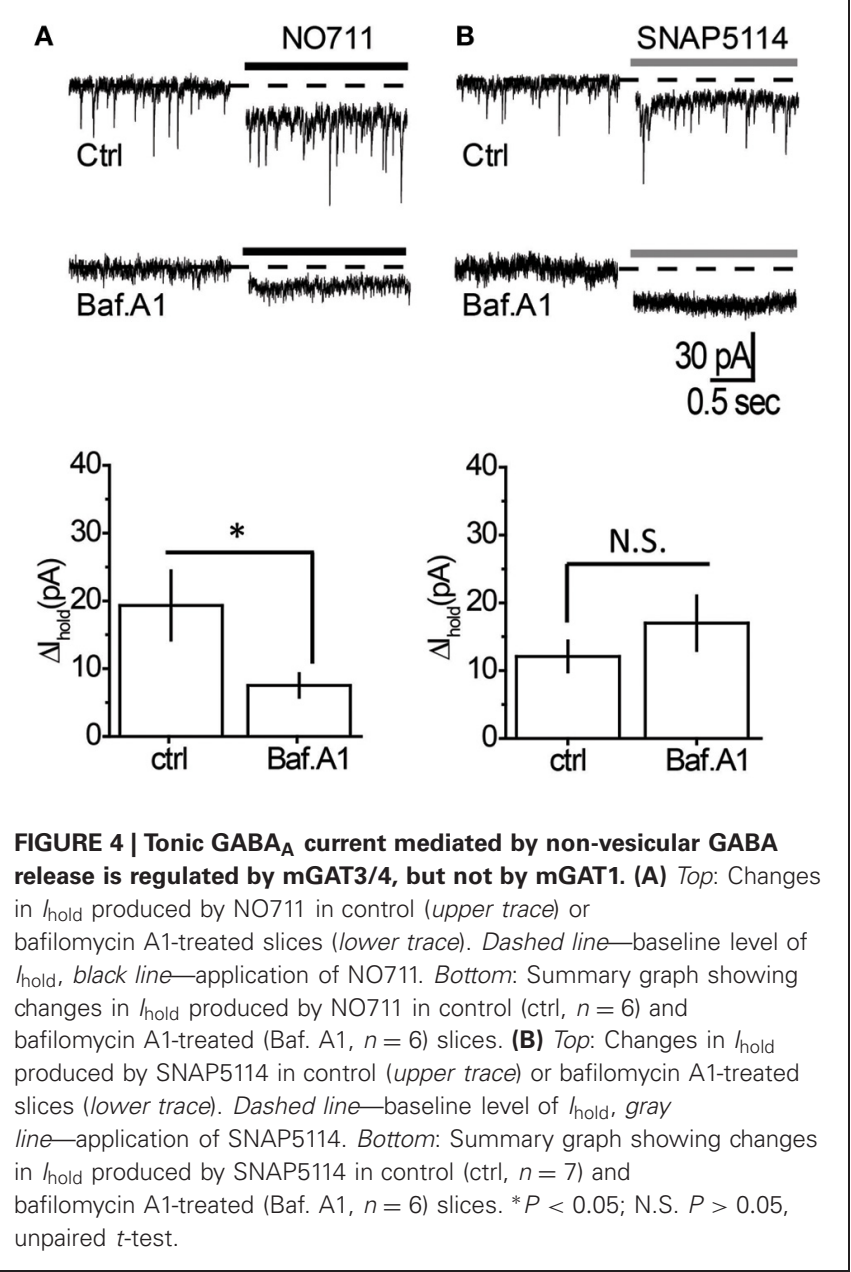

from non-vesicular sources. We then asked whether the effect of bafilomycin A1 depended on which type of GABA transporters was blocked. Using a Two-Way ANOVA we found that the interaction between bafilomycin A1 and uptake inhibitor is significant $\left[F_{(1,21)}=434, p=0.025\right]$, indicating that bafilomycin A1 has a significantly greater effect in the presence of a mGAT1 blocker than mGAT3/4 blocker and suggesting also that mGAT1 mainly controls the uptake of GABA released by exocytosis.

\section{mGAT1 REGULATES GABA ORIGINATING FROM VESICULAR SOURCES}

It remains possible, however, that when vesicular release is increased, mGAT3/4 can contribute to the uptake of GABA escaping from the synaptic cleft together with mGAT1. To test this possibility, synaptic GABA release was enhanced with the mutant $\alpha$-latrotoxin (LTX ${ }^{\mathrm{N} 4 \mathrm{C}}$ ) which, unlike the wild-type toxin, does not form pores in the membrane and increases neurotransmitter release by stimulating LTX receptors (most likely latrophilin 1) without neuronal depolarization (Ichtchenko et al., 1998; Capogna et al., 2003; Volynski et al., 2003; Deak et al., 2009). LTX $^{\mathrm{N} 4 \mathrm{C}}$ at a concentration of $0.1 \mathrm{nM}$ increased the frequency of sIPSCs to $144.5 \pm 10.5 \%$ of baseline $(n=7, P=0.004$ paired $t$-test; Figures $5 \mathrm{~A}, \mathbf{B})$. As expected for LTX $^{\mathrm{N} 4 \mathrm{C}}$, which activates latrophilin after a lag-period (Volynski et al., 2004), the observed increase started $5 \mathrm{~min}$ after drug application. No significant change in the sIPSC amplitude was detected (107.6 \pm $7.6 \%$ of baseline, $n=7, P=0.178$ paired $t$-test; Figure $5 \mathrm{C}$ ), indicating that $\mathrm{LTX}^{\mathrm{N} 4 \mathrm{C}}$ did not affect the membrane permeability of the post-synaptic cell. We next tested how changes in vesicular GABA release affect the tonic $\mathrm{GABA}_{\mathrm{A}}$ current. LTX ${ }^{\mathrm{N} 4 \mathrm{C}}$ increased $I_{\text {hold }}$ in the recorded cells to $117.9 \pm 5.1 \%$ of baseline

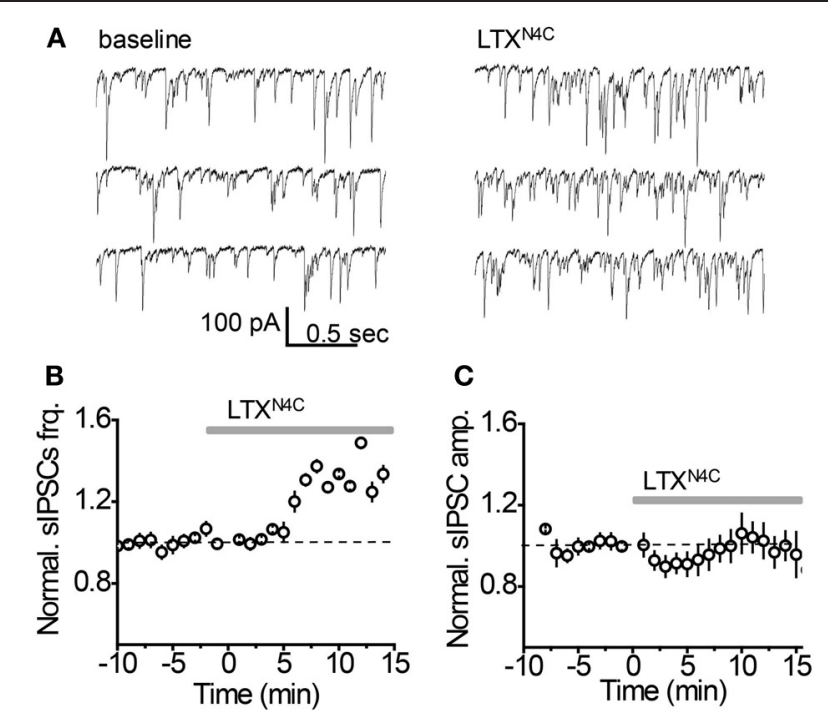

FIGURE 5 | LTX ${ }^{\text {N4C }}$ enhances spontaneous synaptic GABA release. (A) Representative whole-cell recordings of sIPSC from an individual CA1 str. radiatum interneuron before (left) and $10 \mathrm{~min}$ after (right) focal application of LTXN4C . (B) LTXN4C effect on the mean sIPSC frequency normalized to the baseline (dashed line, $n=7$ ). Gray line -application of LTX $^{N 4 C}$. (C) LTX ${ }^{N 4 C}$ effect on mean sIPSC amplitude normalized to the baseline (dashed line, $n=7$ ). Gray line-application of LTX ${ }^{N 4 C}$. 
( $n=6, P=0.007$ paired $t$-test; Figure 6A). The time-course of this increase followed the time-course of the change in sIPSC frequency (Figure 6A, compare to Figure 5B). The LTX ${ }^{\mathrm{N} 4 \mathrm{C}}$ effect on $I_{\text {hold }}$ was blocked by picrotoxin $\left(99.58 \pm 7.27 \%\right.$ of $I_{\text {hold }}$ in picrotoxin, $n=4, P=0.29$ paired $t$-test) or by bicuculline (100.9 \pm $3.6 \%$ of $I_{\text {hold }}$ in bicuculline, $n=4, P=0.48$ paired $t$-test), indicating that the observed change in $I_{\text {hold }}$ was mediated by

A
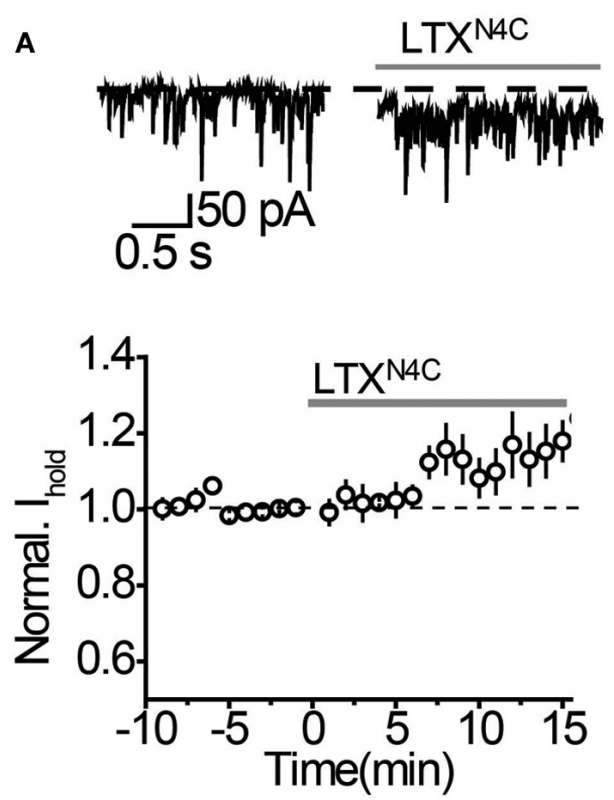

B

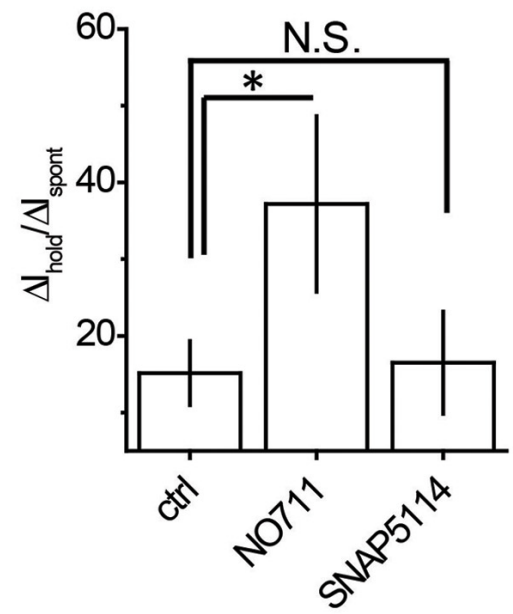

FIGURE 6 | Tonic GABA $A$ current produced by an increase in vesicular GABA release is regulated by mGAT1, but not mGAT3/4. (A) Top: Representative traces showing an increase in / hold 10 min after LTX ${ }^{N 4 C}$ (gray line). Bottom: Time-course of normalized / hold before and during LTX ${ }^{N 4 C}$ application $(n=7)$. Dashed line — baseline /hold, gray line - application of LTX ${ }^{N 4 C}$. (B) Summary graphs showing an increase in tonic $G A B A_{A}$ current with increasing synaptic release $\left(\Delta /\right.$ hold $\left./ \Delta I_{\text {spont }}\right)$. The increase in the $\Delta I_{\text {hold }} / \Delta /_{\text {spont }}$ ratio during $\operatorname{NO} 711(n=6)$ application suggests that more GABA escapes the synapses when mGAT1 is blocked. SNAP5114 $(n=7)$ had no effect on the $\Delta /$ hold $/ \Delta I_{\text {spont }}$ ratio, suggesting that mGAT3/4 does not regulate GABA escape from the synapses. ${ }^{*} P<0.05$, N.S. $P>0.05$, unpaired $t$-test.
$\mathrm{GABA}_{\mathrm{A}}$ receptors (Figure 7). To estimate the proportion of the tonic $\mathrm{GABA}_{\mathrm{A}}$ current produced by enhanced vesicular GABA release, we calculated the ratio between the change in $I_{\text {hold }}$ and the change in $I_{\text {spont }}\left[\Delta I_{\text {hold }} / \Delta I_{\text {spont }}\right.$, where $I_{\text {spont }}$ is the timeaveraged current mediated by sIPSC calculated as the product of the mean charge transfer of sIPSCs and their frequency (Semyanov et al., 2003; Song et al., 2011)]. In control conditions this ratio was $15.14 \pm 4(n=8)$, suggesting that $I_{\text {hold }}$ changes by approximately $15 \mathrm{pA}$ per $1 \mathrm{pA}$ change in $I_{\text {spont }}$. When GABA uptake is blocked, an increase in $\Delta I_{\text {hold }} / \Delta I_{\text {spont }}$ ratio would be expected, indicating that more GABA can escape the synaptic cleft. Since IPSC shape (and thus $I_{\text {spont }}$ ) can change in the presence of GABA uptake blockers, we added the uptake blocker first and then measured the effect of $\mathrm{LTX}^{\mathrm{N} 4 \mathrm{C}}$. The $\Delta I_{\text {hold }} / \Delta I_{\text {spont }}$ ratio was increased approximately two-fold in the presence of NO711 (37.20 $\pm 11.45, n=7, P=0.04$ for difference from control, unpaired $t$-test), but was not significantly affected in the presence of SNAP5114 (16.48 $\pm 6.67, n=5$, $P=0.11$ for difference from control, unpaired $t$-test), suggesting that mGAT1, but not mGAT3/4, is responsible for limiting GABA spillover, even with increased levels of synaptic release (Figure 6B).

\section{DISCUSSION}

Our results demonstrate that mGAT1 and mGAT3/4 transporter types are associated with two different extrasynaptic signaling pathways. mGAT1, but not mGAT3/4, limits synaptic GABA spillover. In contrast, mGAT3/4 makes a larger contribution than mGAT1 to the regulation of GABA released from extrasynaptic sources (Zilberter et al., 1999; Kozlov et al., 2006; Lee et al., 2010).

The different roles of mGAT1 and mGAT3/4 in the regulation of extrasynaptic GABA sources can be explained by their

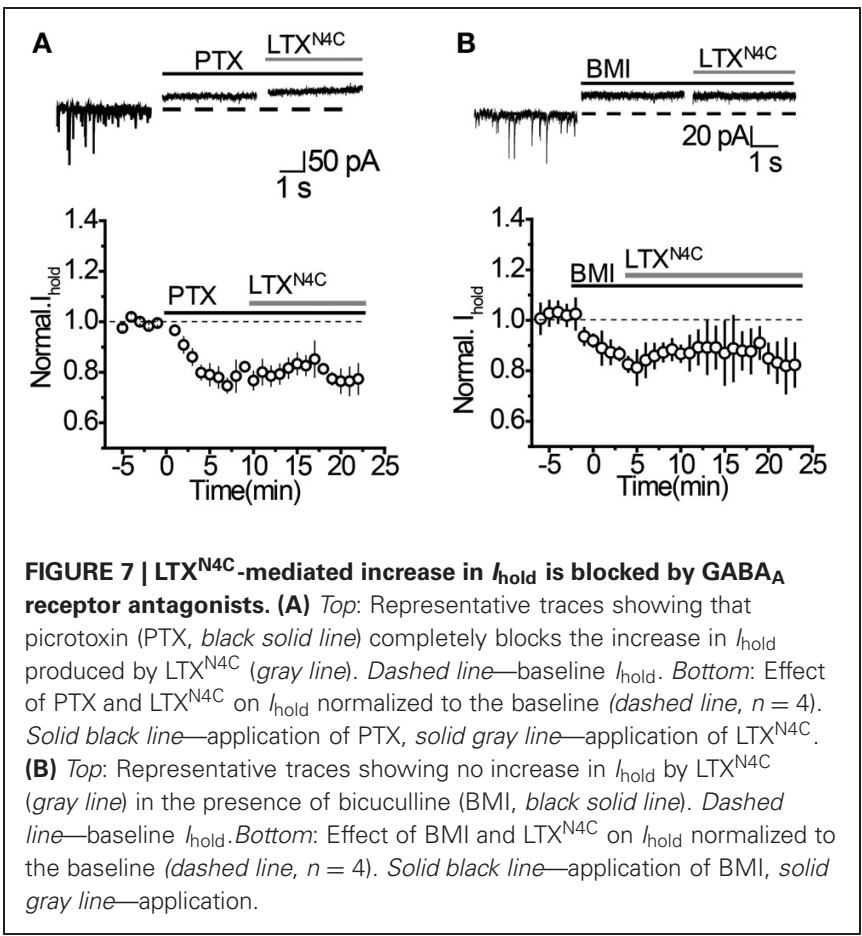


cellular localization. In rat hippocampus, rGAT1 is expressed predominantly in neurons, which express no or only low levels of rGAT3 (Ribak et al., 1996; Heja et al., 2009). In contrast, rGAT3 is strongly expressed in rat hippocampal astrocytes (Heja et al., 2012; Shigetomi et al., 2012). The cell-type specific localization of mGAT1 and mGAT3/4 is responsible for the different regulation of IPSCs by these transporter types. rGAT1 blocker, but not rGAT2/3 blocker, prolongs the decay time of evoked IPSCs in rat neocortex (Keros and Hablitz, 2005) and striatal output neurons (Kirmse et al., 2009). In contrast, in rat globus pallidus, both rGAT1 and rGAT2/3 blockers affect the kinetics of evoked IPSCs (Jin et al., 2011). The interpretation of the transporter blocker effects on synaptic signaling is complicated by possible changes in the presynaptic release probability or in the presynaptic excitability due to elevated ambient GABA concentrations.

Notably, expression patterns of the two transporter types can change independently during physiologic processes, such as memory formation (Tellez et al., 2012), and pathologic processes, such as epilepsy (Cope et al., 2009). In addition to transporter expression, the two GABA uptake systems can be individually regulated by endogenous modulators. For example, zinc, a potent inhibitor of rGAT4, can be released in the hippocampus together with glutamate (Cohen-Kfir et al., 2005). Indeed, zinc increases the extracellular GABA concentration in the hippocampus (Takeda et al., 2004). In addition, glutamate uptake by astrocytes increases the intracellular sodium concentration in these cells (Kirischuk et al., 2012). Increased sodium, in turn, decreases the efficiency of (or even reverses) sodium-dependent GABA uptake by astrocytic rGAT2/3 transporters in the rat (Heja et al., 2012). Such uptake modulation of ambient GABA released from non-vesicular sources would allow for high levels of glutamatergic synaptic excitation to increase tonic $\mathrm{GABA}_{\mathrm{A}}$ conductance in the hippocampus without affecting synaptic GABAergic signaling.

Taken together with our findings, these considerations suggest the existence of two functionally distinct extrasynaptic GABA signaling systems that possess independently regulated uptake machinery. One system is directly operated by GABA escape from the GABAergic synapses and is associated with mGAT1. This system provides direct feedback regulation of GABAergic synaptic activity through regulating the tonic $\mathrm{GABA}_{\mathrm{A}}$ conductance. The second system is operated by other neurotransmitters that can promote non-vesicular GABA release (e.g., by astrocytes), and is regulated by mGAT3/4. This system represents an indirect network feedback (via non-vesicular GABA release), which also results in changes in tonic $\mathrm{GABA}_{\mathrm{A}}$ conductance. Notably, when one of the transporter types is blocked the second type compensates for its loss and takes up GABA originating from both sources. Therefore, when both transporters are blocked their effect on tonic $\mathrm{GABA}_{\mathrm{A}}$ conductance is supra-additive. This opens up the possibility that in cases when GABA release from the vesicular or non-vesicular source overwhelms their "dedicated" transporter type, the other transporter type can assist in GABA clearance. However, we did not find that a moderate increase in vesicular GABA release can overwhelm mGAT1, but it could potentially happen with further increases in GABA release, or in situations when there is a downregulation of mGAT1.

Importantly, we performed the experiments with $G_{A B A}$ receptors blocked. Activation of these receptors may also depend on the source of extracellular GABA. Indeed, different roles played by rGAT1 and $\mathrm{rGAT} 3$ in regulating $\mathrm{GABA}_{\mathrm{B}}$ receptor activation have been shown in thalamus (Beenhakker and Huguenard, 2010). Thus two GABA sources and two types of GABA transporters can form a specific agonist "template" for extrasynaptic $\mathrm{GABA}_{\mathrm{A}}$ and $\mathrm{GABA}_{\mathrm{B}}$ receptor activation (Semyanov, 2008).

Another important question is the identity of the recorded interneurons. We identified these cells solely by their location in CA1 str.radiatum and non-pyramidal shape, and did not differentiate different interneuronal subtypes (Klausberger and Somogyi, 2008). It is possible that distinct interneurons may express tonic $\mathrm{GABA}_{\mathrm{A}}$ currents to differing extents as has been shown in neocortex (Vardya et al., 2008). Potentially, the contribution of vesicular and non-vesicular sources of GABA may also differ among different interneuron subtypes and so tonic $\mathrm{GABA}_{\mathrm{A}}$ conductances could be regulated differently by the two transporter systems. This question is an important subject for future functional studies, especially those which aim to apply our finding to the identification of novel drug targets. Indeed, the functional difference between mGAT1 and mGAT3/4 prompts a refinement of therapeutic targets for drugs acting on the GABA uptake systems. For example, the anti-epileptic drug, tiagabine, a mGAT1 blocker, increases GABA spillover, and can affect the time course of IPSCs (Walker and Kullmann, 2012). Because IPSCs are involved in synaptic computations, tiagabine can potentially have unwanted effects on synaptic network operation. A selective mGAT3/4 transporter blocker should increase extracellular GABA levels without significantly affecting synaptic communication and perhaps lack the side effects characteristic of tiagabine.

\section{AUTHOR CONTRIBUTIONS}

Inseon Song: collection, analysis, and interpretation of most of the data, conception and design of the experiments; Kirill Volynski: preliminary experiments with latrotoxin, interpretation of data; Tanja Brenner: collection and analysis of some supplementary data; Yuri Ushkaryov: production of mutated latrotoxin; Matthew Walker: data interpretation; Alexey Semyanov: project conception, experimental design, data analysis, and data interpretation; All authors discussed the results, contributed to the writing of the article and have approved its final version. All experiments except production of mutated latrotoxin production were performed in RIKEN BSI, Japan.

\section{ACKNOWLEDGMENTS}

The authors thank Ivan Pavlov and Astrid Linthorst for comments on the manuscript. This work was supported by the Wellcome Trust grant to Matthew Walker and Alexey Semyanov and by the MRC to Kirill Volynski. 


\section{REFERENCES}

Banke, T. G., and McBain, C. J. (2006). GABAergic input onto CA3 hippocampal interneurons remains shunting throughout development. J. Neurosci. 26, 11720-11725.

Beenhakker, M. P., and Huguenard, J. R. (2010). Astrocytes as gatekeepers of GABAB receptor function. J. Neurosci. 30, 15262-15276.

Capogna, M., Volynski, K. E., Emptage, N. J., and Ushkaryov, Y. A. (2003). The alpha-latrotoxin mutant LTXN4C enhances spontaneous and evoked transmitter release in CA3 pyramidal neurons. J. Neurosci. 23, 4044-4053.

Cohen-Kfir, E., Lee, W., Eskandari, S., and Nelson, N. (2005). Zinc inhibition of gamma-aminobutyric acid transporter 4 (GAT4) reveals a link between excitatory and inhibitory neurotransmission. Proc. Natl. Acad. Sci. U.S.A. 102, 6154-6159.

Cope, D. W., Di Giovanni, G., Fyson, S. J., Orban, G., Errington, A. C., Lorincz, M. L., et al. (2009). Enhanced tonic GABAA inhibition in typical absence epilepsy. Nat. Med. 15, 1392-1398.

Deak, F., Liu, X., Khvotchev, M., Li, G., Kavalali, E. T., Sugita, S., et al. (2009). Alpha-latrotoxin stimulates a novel pathway of $\mathrm{Ca} 2+-$ dependent synaptic exocytosis independent of the classical synaptic fusion machinery. J. Neurosci. 29 8639-8648.

Farrant, M., and Nusser, Z. (2005). Variations on an inhibitory theme: phasic and tonic activation of GABA(A) receptors. Nat. Rev. Neurosci. 6, 215-229.

Glickfeld, L. L., Roberts, J. D., Somogyi, P., and Scanziani, M. (2009). Interneurons hyperpolarize pyramidal cells along their entire somatodendritic axis. Nat. Neurosci. $12,21-23$.

Glykys, J., and Mody, I. (2007a). Activation of GABAA receptors: views from outside the synaptic cleft. Neuron 56, 763-770.

Glykys, J., and Mody, I. (2007b). The main source of ambient GABA responsible for tonic inhibition in the mouse hippocampus. J. Physiol. 582, 1163-1178.

Heja, L., Barabas, P., Nyitrai, G., Kekesi, K. A., Lasztoczi, B., Toke, O., et al. (2009). Glutamate uptake triggers transporter-mediated GABA release from astrocytes. PLoS ONE 4:e7153. doi: 10.1371/journal.pone.0007153

Heja, L., Nyitrai, G., Kekesi, O., Dobolyi, A., Szabo, P., Fiath, R., et al. (2012). Astrocytes convert network excitation to tonic inhibition of neurons. BMC Biol. 10:26. doi: 10.1186/1741-7007-10-26

Ichtchenko, K., Khvotchev, M. Kiyatkin, N., Simpson, L., Sugita, S., and Sudhof, T. C. (1998). alpha-latrotoxin action probed with recombinant toxin: receptors recruit alpha-latrotoxin but do not transduce an exocytotic signal. EMBO J. 17, 6188-6199.

Jin, X. T., Pare, J. F., and Smith, Y. (2011). Differential localization and function of GABA transporters, GAT- 1 and GAT-3, in the rat globus pallidus. Eur. J. Neurosci. 33, 1504-1518.

Johnson, L. S., Dunn, K. W., Pytowski, B., and McGraw, T. E. (1993). Endosome acidification and receptor trafficking: bafilomycin Al slows receptor externalization by a mechanism involving the receptor's internalization motif. Mol. Biol. Cell 4, 1251-1266.

Keros, S., and Hablitz, J. J. (2005) Subtype-specific GABA transporter antagonists synergistically modulate phasic and tonic GABAA conductances in rat neocortex. J. Neurophysiol. 94, 2073-2085.

Kirischuk, S., Parpura, V., and Verkhratsky, A. (2012). Sodium dynamics: another key to astroglial excitability? Trends Neurosci. 35, 497-506.

Kirmse, K., Kirischuk, S., and Grantyn, R. (2009). Role of GABA transporter 3 in GABAergic synaptic transmission at striatal output neurons. Synapse 63, 921-929.

Klausberger, T., and Somogyi, P. (2008). Neuronal diversity and temporal dynamics: the unity of hippocampal circuit operations. Science 321, 53-57.

Kozlov, A. S., Angulo, M. C., Audinat, E., and Charpak, S. (2006). Target cell-specific modulation of neuronal activity by astrocytes. Proc. Natl. Acad. Sci. U.S.A. 103, 10058-10063.

Kullmann, D. M. (2011). Interneuron networks in the hippocampus. Curr. Opin. Neurobiol. 21, 709-716.

Lee, S., Yoon, B. E., Berglund, K., Oh, S. J., Park, H., Shin, H. S., et al. (2010). Channel-mediated tonic GABA release from glia. Science 330, 790-796.

Michelson, H. B., and Wong, R. K. (1991). Excitatory synaptic responses mediated by GABAA receptors in the hippocampus. Science 253, 1420-1423.

Presley, J. F., Mayor, S., McGraw, T. E., Dunn, K. W., and Maxfield, F. R. (1997). Bafilomycin Al treatment retards transferrin receptor recycling more than bulk membrane recycling. J. Biol. Chem. 272, 13929-13936.

Ribak, C. E., Tong, W. M., and Brecha N. C. (1996). GABA plasma membrane transporters, GAT-1 and GAT-3, display different distributions in the rat hippocampus. J. Comp. Neurol. 367, 595-606.

Scimemi, A., Semyanov, A., Sperk, G. Kullmann, D. M., and Walker, M. C. (2005). Multiple and plastic receptors mediate tonic GABAA receptor currents in the hippocampus. J. Neurosci. 25, 10016-10024.

Semyanov, A. (2008). Can diffuse extrasynaptic signaling form a guiding template? Neurochem. Int. 52, 31-33.

Semyanov, A., Walker, M. C., and Kullmann, D. M. (2003). GABA uptake regulates cortical excitability via cell type-specific tonic inhibition. Nat. Neurosci. 6, 484-490.

Semyanov, A., Walker, M. C. Kullmann, D. M., and Silver, R. A. (2004). Tonically active GABA A receptors: modulating gain and maintaining the tone. Trends Neurosci. 27, 262-269.

Shigetomi, E., Tong, X., Kwan, K. Y., Corey, D. P., and Khakh, B. S. (2012). TRPAl channels regulate astrocyte resting calcium and inhibitory synapse efficacy through GAT-3. Nat. Neurosci. 15, 70-80.

Silva, J. P., Suckling, J., and Ushkaryov, Y. (2009). Penelope's web: using alpha-latrotoxin to untangle the mysteries of exocytosis. J. Neurochem. 111, 275-290.

Song, I., Savtchenko, L., and Semyanov, A. (2011). Tonic excitation or inhibition is set by $\operatorname{GABA}(\mathrm{A})$ conductance in hippocampal interneurons. Nat. Commun. 2:376 doi: $10.1038 /$ ncomms1377

Takeda, A., Minami, A., Seki, Y., and Oku, N. (2004). Differential effects of zinc on glutamatergic and GABAergic neurotransmitter systems in the hippocampus. J. Neurosci. Res. 75, 225-229.

Tellez, R., Gomez-Viquez, L., and Meneses, A. (2012). GABA, glutamate, dopamine and serotonin transporters expression on memory formation and amnesia. Neurobiol. Learn. Mem. 97, 189-201.

Ushkaryov, Y. A., Rohou, A., and Sugita, S. (2008). Alpha-Latrotoxin and its receptors. Handb. Exp. Pharmacol. 184, 171-206.

Vardya, I., Drasbek, K. R., Dosa, Z., and Jensen, K. (2008). Cell type-specific GABA A receptormediated tonic inhibition in mouse neocortex. J. Neurophysiol. 100 526-532.
Vida, I., Bartos, M., and Jonas, P. (2006). Shunting inhibition improves robustness of gamma oscillations in hippocampal interneuron networks by homogenizing firing rates. Neuron 49, 107-117.

Volynski, K. E., Capogna, M., Ashton, A. C., Thomson, D., Orlova, E. V., Manser, C. F., et al. (2003). Mutant alpha-latrotoxin (LTXN4C) does not form pores and causes secretion by receptor stimulation: this action does not require neurexins. J. Biol. Chem. 278, 31058-31066.

Volynski, K. E., Silva, J. P., Lelianova, V. G., Atiqur Rahman, M., Hopkins, C., and Ushkaryov, Y. A. (2004). Latrophilin fragments behave as independent proteins that associate and signal on binding of LTX(N4C). EMBO J. 23, 4423-4433.

Walker, M. C., and Kullmann, D. M. (2012). "Tonic $\mathrm{GABA}_{\mathrm{A}}$ receptormediated signaling in epilepsy," in Jasper's Basic Mechanisms of the Epilepsies, 4th Edn, eds J. L. Noebels, M. Avoli, M. A. Rogawski, R. W. Olsen, and A. V. Delgado-Escueta (Bethesda, MD: National Center for Biotechnology Information).

Walker, M. C., and Semyanov, A. (2008). Regulation of excitability by extrasynaptic GABA(A) receptors. Results Probl. Cell Differ. 44, 29-48.

Zilberter, Y., Kaiser, K. M., and Sakmann, B. (1999). Dendritic GABA release depresses excitatory transmission between layer $2 / 3$ pyramidal and bitufted neurons in rat neocortex. Neuron 24, 979-988.

Conflict of Interest Statement: The authors declare that the research was conducted in the absence of any commercial or financial relationships that could be construed as a potential conflict of interest.

Received: 18 December 2012; accepted: 25 February 2013; published online: 13 March 2013

Citation: Song I, Volynski K, Brenner T, Ushkaryov Y, Walker $M$ and Semyanov A (2013) Different transporter systems regulate extracellular GABA from vesicular and non-vesicular sources. Front. Cell. Neurosci. 7:23. doi: 10.3389/fncel. 2013.00023

Copyright (C) 2013 Song, Volynski, Brenner, Ushkaryov, Walker and Semyanov. This is an open-access article distributed under the terms of the Creative Commons Attribution License, which permits use, distribution and reproduction in other forums, provided the original authors and source are credited and subject to any copyright notices concerning any third-party graphics etc. 